\title{
QUALIDADE E RENDIMENTO DA MUSSSARELA EM TEMPOS DE ARMAZENAMENTO SOB REFRIGERAÇÃO DA MASSA ACIDIFICADA
}

\section{QUALITY AND PERFORMANCE OF MUSSSARELA IN TIMES OF ACIDIFIED MASS UNDER REFRIGERATED STORAGE}

\author{
Bruno Gomes Mendes ${ }^{1}$; Kátia Aparecida Castro ${ }^{2}$ Katrine Assunção de Lima Silva ${ }^{3}$; Alexandre Igor de \\ Azevedo Pereira ${ }^{4}$; Joice Vinhal Costa Orsine ${ }^{5}$ \\ Instituto Federal Goiano - IFGoiano - Campus Urutaí - Brasil joicevinhal@ gmail.com
}

\begin{abstract}
Resumo
Antes da etapa de filagem da Mussarela, a massa dessorada deve ser acidificada, e este tempo geralmente é realizado em três horas. Objetivou-se com este trabalho avaliar a interferência da refrigeração da massa acidificada, antes do processo de filagem, sobre as características reológicas da massa de mussarela e sobre o rendimento final do queijo. Foram elaborados quatro lotes: Mc (controle), com tempo de acidificação sob refrigeração de três horas; M1 (12h), M2 (24h) e M3 (36h). Verificou-se que, quanto maior o tempo sob refrigeração durante a acidificação da massa, que antecede a etapa de filagem, maior é a perda da umidade e maior a perda de gordura na água de filagem. Dessa forma, o rendimento industrial do queijo é reduzido, diminuindo-se o lucro da indústria laticinista. Concluiu-se então que são necessários investimentos no setor de filagem da indústria em estudo com intuito de promover a redução do tempo de acidificação da massa dessorada, de forma a garantir uma maximização dos lucros da empresa.
\end{abstract}

Palavras-chave: queijos; tecnologia de laticínios; maximização de lucros.

\section{Introdução}

Uma das formas mais antigas de conservação do leite é por meio da produção de queijo, que pode ser definido como um produto fresco ou maturado, obtido pela coagulação natural do leite ou pela ação das enzimas do coalho, separado do soro e amadurecido durante tempo variável. É considerado um alimento altamente nutritivo, por apresentar em sua composição quantidade considerável de proteínas, gorduras, sais minerais e vitaminas (CAVALCANTE, 2004).

No Brasil, o principal destino do leite produzido é destinado à fabricação de queijos, representando 34\% do total de leite produzido em território nacional (EMBRAPA, 2010). No ano de 2011 foram produzidos aproximadamente 30,7 milhões de toneladas de queijos no Brasil, o que 
o tornou o maior produtor do produto da América do Sul, seguido pela Argentina com 11,1 milhões de toneladas (FAO, 2012).

A Mussarela encontra-se entre os queijos mais consumidos no Brasil, devido à sua utilização como ingrediente em pizzas. O formato tradicional desse queijo é o paralelepípedo, entretanto, outras formas também podem ser encontradas, como bolinha, palito e nozinho utilizados no consumo de mesa. É um queijo obtido por filagem de uma massa acidificada, com características finais de maciez e elevada umidade, quando apresenta, em média, $43 \%$ a $46 \%$ de umidade; $22 \%$ a $24 \%$ de gordura; teor de sal variando entre 1,6\% a 1,8\%; e pH entre 5,1 e 5,3 (SILVA, 2005).

A Mussarela é produzida com leite pasteurizado, padronizando-se o teor de gordura a 3\%. Sua massa é filada quando, posteriormente à dessoragem, ocorre o fatiamento e aquecimento, misturando as fatias até a formação de um bloco liso e homogêneo com consistência firme e compacta, apresentando cor esbranquiçada e sabor levemente ácido. Seu formato e peso são variáveis e deve ser conservado sob refrigeração, em temperaturas de até $10^{\circ} \mathrm{C}$ (PERRY, 2004).

O processamento do queijo mussarela pode diferir muito entre as indústrias por fatores como: tecnologia disponível, volume diário de produção, mão-de-obra especializada, entre outros. Considerando-se que o aumento da produção de Mussarela pelas indústrias pode ocasionar problemas com relação à filagem da massa no $\mathrm{pH}$ ideal, gerando a necessidade de se refrigerar a massa com o intuito de diminuir a atividade fermentativa dos micro-organismos e estabilizar o $\mathrm{pH}$, objetivo-se com estudo avaliar a influência da refrigeração sobre as características reológicas da massa de Mussarela acidificada, além do rendimento final do queijo.

\section{Material e Métodos}

O estudo foi realizado na indústria Laticínios JL, situada em Orizona - GO, no período de Novembro a Dezembro de 2011.

O leite utilizado no estudo foi obtido de produtores do sudeste goiano, credenciados pelo laticínio. A qualidade da matéria-prima foi certificada por meio de análises físico-químicas e microbiológicas realizadas no laboratório do laticíneo em questão. Para o estudo, foram utilizados ao todo, 40.000 litros de leite.

As análises físico-químicas seguiram os padrões exigidos por Brasil (2006), para as análises de acidez titulável, gordura, proteína, densidade, crioscopia, $\mathrm{pH}$, fosfatase alcalina, peroxidase, ESD (extrato seco desengordurado) e para EST (extrato seco total) foi utilizada a fórmula descrita por Furtado (1994); as análises microbiológicas (psicrotróficos, coliformes termotolerantes) do leite foram realizadas de acordo com o preconizado por Brasil (2003). 


\subsection{Obtenção da massa de Mussarela}

Primeiramente o leite foi pasteurizado a $72-75^{\circ} \mathrm{C}$ por 15 segundos e resfriado em temperatura de $35^{\circ} \mathrm{C}$ utilizando-se trocador de calor a placas, quando foi encaminhado para a padronizadoralhomogeneizadora. Em seguida o leite foi enviado, por tubulação fechada, para os tanques de fabricação tipo "Queijomatic" (Marca Solutec), com capacidade para 10.000 litros de leite.

Foram adicionados como ingredientes: 4L de cloreto de cálcio (Marca Bela Vista), fermento láctico (St. Thermophillus + L. Bulgaricus) a base 1,5\%, e 115g de coalho (Marca Albamax). Após a adição do coalho, agitou-se o leite, utilizando-se liras mecânicas por cinco minutos para a dissolução completa das enzimas no leite. Após esse tempo, as liras foram desligadas e esperou-se 45 minutos para a coagulação do leite. Cortou-se a coalhada até que esta atingisse tamanho uniforme, de aproximadamente $1,5 \mathrm{~cm}$ x $2 \mathrm{~cm}$ de aresta. Iniciou-se agitação lenta e contínua, com injeção de vapor indireto, até atingir temperatura de $44^{\circ} \mathrm{C}$, procedendo então agitação rápida. A massa foi então encaminhada à drenoprensada, utilizando-se ar comprimido com pressão de 50-60 libras/pol, por 20 minutos. Após esse período a massa foi cortada em blocos quadrados de aproximadamente $20 \mathrm{Kg}$, e estes foram acondicionados em prateleiras de inox, até que atingissem pH de filagem, próximo a 5,0 e elasticidade ideal.

\subsection{Refrigeração da massa acidificada de Mussarela}

Para o estudo, foram separados quatro lotes de massa acidificada para a elaboração do queijo Mussarela, denominados M1, M2, M3 e controle (Mc), conforme apresentado na Tabela 1.

Tabela 1 - Tempo de refrigeração da massa acidificada que precede o processo de filagem do queijo Mussarela.

\begin{tabular}{cc}
\hline Lote & Tempo de refrigeração após obtenção da massa acidificada (h) \\
\hline Mc & 3 \\
M1 & 12 \\
M2 & 24 \\
M3 & 36 \\
\hline
\end{tabular}

Para cada lote foram utilizados 10.000 litros de leite, sendo este o volume máximo de produção de uma "Queijomatic". O tempo de três horas de refrigeração após acidificação da massa do lote controle $(\mathrm{Mc})$, antes da filagem, foi estipulado como padrão devido à sua maior frequência de utilização no laticínio em estudo. 


\subsection{Filagem e enformagem da massa acidificada}

Procedeu-se então a filagem da massa, em monobloco (Marca Trevi), utilizando-se água a $65^{\circ} \mathrm{C}$ e posterior enformagem em formas retangulares de $4 \mathrm{Kg}$.

\subsubsection{Análises físico-químicas na massa acidificada filada}

As massas acidificadas refrigeradas foram analisadas quanto ao teor de gordura, umidade e pH. Posteriormente, seguiu-se a filagem, sendo coletadas amostras da água de filagem para posterior avaliação do teor de gordura e acidez, conforme metodologias apresentadas anteriormente no item 3.2 .

\subsection{Obtenção do queijo Mussarela}

Logo após a filagem, os queijos foram resfriados em água gelada $\left(10^{\circ} \mathrm{C}\right)$ por 20 minutos e, em seguida, seguiram-se para imersão úmida em salmoura com 22\% de sal, por um período de 24 horas em temperatura de $12^{\circ} \mathrm{C}$.

Após esse período, os queijos permaneceram por dois dias em câmara fria de maturação a $6^{\circ} \mathrm{C}$, sendo posteriormente acondicionados em embalagem termoencolhível (Marca Criovac). Depois de embalados, foram estocados em câmara fria a $4^{\circ} \mathrm{C}$. Os queijos Mussarelas passaram por um período de estabilização de 20 dias e, posteriormente, foram submetidos às análises de umidade, gordura, EST, ESD, GES e pH, conforme metodologias apresentadas no item 2.

\subsection{Cálculo de rendimento}

Para cálculo do rendimento de cada queijo, utilizou-se metodologia de Furtado (2005): I) Volume de litro de leite necessário para elaboração de um quilo de queijo, quando divide-se o volume de leite utilizado pela massa dos queijos obtidos; II) A massa em gramas de sólidos totais do queijo por litro de leite. Para tanto empregou-se a equação:

$$
\mathrm{R}(\mathrm{g} \mathrm{ST} / \mathrm{L})=\frac{\mathrm{P} \times \mathrm{ST} \times 100}{\mathrm{~V}}
$$

Onde:

$\mathrm{R}$ - Rendimento

P- quilos de queijos obtidos 
ST- porcentagem de extrato seco total dos queijos

V - volume do leite utilizado

\section{Resultados e discussão}

\subsection{Qualidade do leite}

A qualidade físico-química do leite utilizado no presente estudo foi apresentada na Tabela 2.

Tabela 2 - Qualidade físico-química do leite utilizado para fabricação da Mussarela.

\begin{tabular}{ccccccc}
\hline Leite & $\begin{array}{c}\text { Gordura } \\
(\boldsymbol{\%})\end{array}$ & $\begin{array}{c}\text { Densidade } \\
(\mathbf{g} / \mathbf{L})\end{array}$ & Crioscopia $\left({ }^{\mathbf{H}}\right)$ & $\begin{array}{c}\text { EST } \\
(\boldsymbol{\%})\end{array}$ & $\begin{array}{c}\text { ESD } \\
(\boldsymbol{\%})\end{array}$ & $\begin{array}{c}\text { Acidez } \\
\left(\mathbf{D}^{\mathbf{o}}\right)\end{array}$ \\
\hline Mc & $2,86 \pm 0,03^{\mathrm{a}}$ & $31,20 \pm 0,05 \mathrm{~B}$ & $-0,5437 \pm 0,00 \mathrm{~A}$ & $11,51 \pm 0,01 \mathrm{~A}$ & $8,61 \pm 0,02 \mathrm{~B}$ & $16,33 \pm 0,33 \mathrm{~A}$ \\
M1 & $2,83 \pm 0,03^{\mathrm{a}}$ & $31,70 \pm 0,05 \mathrm{~A}$ & $-0,5423 \pm 0,00 \mathrm{AB}$ & $10,57 \pm 0,02 \mathrm{~A}$ & $8,74 \pm 0,01 \mathrm{~A}$ & $16,00 \pm 0,00 \mathrm{~A}$ \\
M2 & $2,80 \pm 0,00 \mathrm{~A}$ & $31,53 \pm 0,08 \mathrm{~A}$ & $-0,5440 \pm 0,00 \mathrm{~A}$ & $11,49 \pm 0,02 \mathrm{~A}$ & $8,69 \pm 0,02 \mathrm{~A}$ & $16 \pm 0,00 \mathrm{~A}$ \\
M3 & $2,76 \pm 0,03^{\mathrm{a}}$ & $31,63 \pm 0,03 \mathrm{~A}$ & $-0,5470 \pm 0,00 \mathrm{~B}$ & $11,47 \pm 0,03 \mathrm{~A}$ & $8,71 \pm 0,00 \mathrm{~A}$ & $16 \pm 0,00 \mathrm{~A}$ \\
\hline F & 2,22 & 12,66 & 7,51 & 2,71 & 12,79 & 1,00 \\
P & 0,16 & 0,02 & 0,01 & 0,11 & 0,01 & 0,44 \\
CV & 1,77 & 0,34 & 0,17 & 0,39 & 0,31 & 1,79
\end{tabular}

* Mc: Mussarela produzida com massa acidificada após 3h em refrigeração; M1: Mussarela produzida com massa acidificada após 12h em refrigeração; M2: Mussarela produzida com massa acidificada após 24h em refrigeração; M3: Mussarela produzida com massa acidificada após $36 \mathrm{~h}$ em refrigeração.

* UMD: Umidade no Extrato Seco; EST: Extrato Seco Total; ESD: Extrato Seco Desengordurado; GES: Gordura no Extrato Seco

* Teste de Tuckey $(\mathrm{p}=0,05)$

* F:Valor do teste ; $p=0,05 ; P$ : Significância; CV: Coeficiente de variação.

Com relação à qualidade da matéria-prima utilizada na fabricação dos quatro lotes estudados, todos os resultados se encontraram dentro dos padrões físico-químicos estabelecidos pela Instrução Normativa n51 de 2002 (BRASIL, 2002). Quando analisado o teor de godura, verifica-se que as análises foram realizadas após a padronização do leite, que geralmente é estabelecida pela empresa para valores que variam de 2,7 à 2,9. Em estudo realizado por Valle et al. (2004), o autor acompanhou a fabricação de Mussarela com diferentes concentrações de gordura, e verificou que os melhores valores lipídicos para a qualidade do queijo estão estabelecidos entre 2,5 e 3,0.

Para o leite, a acidez máxima aceita pela legislação é de $18^{\circ} \mathrm{D}$, o que pode ser observado para todos os resultados de acidez dos lotes envolvidos no estudo. Quando observados os sólidos do leite, verifica-se que estes também se manteviveram acima dos padrões exigidos pela legislação, de $11 \%$, assim como os valores esperados para a densidade (BRASIL, 2002).

A análise de qualidade e sanidade do leite utilizado na fabricação é muito importante pois os produtos resultantes dependem de matéria-prima de boa qualidade, por isso o leite destinado à 
fabricação deve obedecer os padrões estabelecidos na legislação (BRASIL, 2002), e essa qualidade está diretamente relacionada às condições de sanidade do rebanho e à produção higiênica do leite, englobando o local de ordenha, o ordenhador, o vasilhame, o acondicionamento, a conservação e o transporte do mesmo (BRAGANÇA e SOUZA, 2001). A qualidade microbiológica do leite utilizado na fabricação dos quatro lotes de Mussarela (Mc, M1, M2, M3 e M4) foi apresentada na Tabela 3.

Tabela 3 - Qualidade microbiológica do leite utilizado para a produção da Mussarela.

\begin{tabular}{ccc}
\hline Leite & Psicrotróficos & Coliformes termotolerantes \\
\hline Mc & Ausente & Ausente \\
M1 & Ausente & Ausente \\
M2 & Ausente & Ausente \\
M3 & Ausente & Ausente
\end{tabular}

* Mc: Mussarela produzida com massa acidificada após 3h em refrigeração; M1: Mussarela produzida com massa acidificada após 12h em refrigeração; M2: Mussarela produzida com massa acidificada após 24h em refrigeração; M3: Mussarela produzida com massa acidificada após 36h em refrigeração.

Pode-se observar, na Tabela 3, que o leite utilizado na fabricação da Mussarela do presente estudo apresentada ótima condição microbiológica, tanto para coliformes termotolerantes quanto para psicrotróficos, o que indica a sanidade da matéria-prima.

De acordo com Furtado (1994), a integridade microbiológica do leite é muito importante, uma vez que elevadas contagens de micro-organismos na matéria-prima utilizada para fabricação de queijos representa um grande problema para as indústrias brasileiras. Além de representar um problema de saúde pública, provocam o aumento da velocidade de deterioração do produto, diminuem o rendimento e afetam a qualidade final do queijo.

Segundo Prata (2001), a exigência da legislação brasileira para que seja realizada a estocagem em temperatura de refrigeração do leite, anteriormente a seu processamento, faz com que seja reduzida a incidência de coliformes termotolerantes no leite, uma vez que esses microorganismos necessitam de temperaturas mais elevadas para se desenvolverem.

Resfriar leite de má qualidade torna-se um grande problema, pois se cria o ambiente perfeito para a proliferação de bactérias psicotróficas (PRATA 2001). Apesar de que as bactérias psicotróficas sejam destruídas durante o processo de pasteurização do leite, as enzimas termoresistentes, como lipases e proteases, previamente produzidas, são capazes de promover alteração de odor no leite, perda de firmeza no coágulo para a fabricação de queijo, sabor amargo aos queijos e rancidez (FURTADO, 1994).

\subsection{Características da massa acidificada}


Na Tabela 4 foram apresentados os resultados das análises da massa antes do processo de filagem.

Tabela 4 - Características físico-químicas da massa de queijo, antes do processo de filagem.

\begin{tabular}{cccccc}
\hline $\begin{array}{c}\text { Massa de } \\
\text { queijo }\end{array}$ & $\begin{array}{c}\text { Umidade } \\
(\boldsymbol{\%})\end{array}$ & $\begin{array}{c}\text { Gordura } \\
(\boldsymbol{\%})\end{array}$ & $\mathbf{p H}$ & $\begin{array}{c}\text { EST } \\
(\%)\end{array}$ & $\begin{array}{c}\text { ESD } \\
(\%)\end{array}$ \\
\hline Mc & $48 \pm 0,00 \mathrm{~A}$ & $24,33 \pm 0,33 \mathrm{AB}$ & $5,10 \pm 0,00 \mathrm{~A}$ & $52 \pm 0,00 \mathrm{C}$ & $27,66 \pm 0,33 \mathrm{C}$ \\
M1 & $47,33 \pm 0,33 \mathrm{~A}$ & $25 \pm 0,00 \mathrm{~A}$ & $5,03 \pm 0,03 \mathrm{AB}$ & $52,66 \pm 0,33 \mathrm{C}$ & $27,66 \pm 0,33 \mathrm{C}$ \\
M2 & $44 \pm 0,00 \mathrm{~B}$ & $24,33 \pm 0,33 \mathrm{AB}$ & $5,00 \pm 0,00 \mathrm{~B}$ & $56 \pm 0,00 \mathrm{~B}$ & $31,66 \pm 0,33 \mathrm{C}$ \\
M3 & $42,66 \pm 0,33 \mathrm{C}$ & $23,33 \pm 0,33 \mathrm{~B}$ & $5,00 \pm 0,00 \mathrm{~B}$ & $57,33 \pm 0,33 \mathrm{~A}$ & $34 \pm 0,00 \mathrm{~A}$ \\
\hline F & 119,33 & 5,66 & 8,00 & 119,33 & 117,66 \\
P & 0,01 & 0,02 & 0,01 & 0,01 & 0,01 \\
CV & 0,89 & 2,05 & 0,57 & 0,74 & 1,65
\end{tabular}

* Mc: Mussarela produzida com massa acidificada após 3h em refrigeração; M1: Mussarela produzida com massa acidificada após 12h em refrigeração; M2: Mussarela produzida com massa acidificada após 24h em refrigeração; M3: Mussarela produzida com massa acidificada após 36h em refrigeração.

* UMD: Umidade no Extrato Seco; EST: Extrato Seco Total; ESD: Extrato Seco Desengordurado; GES: Gordura no Extrato Seco

* Teste de Tuckey $(\mathrm{p}=0,05)$

* F: Valor do teste ; $p=0,05$; P: Significância; CV: Coeficiente de variação.

Os resultados obtidos nas análises físico-químicas da massa demonstram uma tendência regressiva da umidade em função do tempo de armazenamento sob refrigeração, pois houve diferença significativa $(\mathrm{p}=0,05)$ entre $\mathrm{Mc}, \mathrm{M} 2$ e $\mathrm{M} 3$ e, conseqüentemente, o aumento do extrato seco total também com diferença significativa $(\mathrm{p}=0,05)$ entre Mc, M2 e M3. Tal fato pode ser explicado pelo ressecamento da massa devido ao prolongamento do tempo de sua estocagem a frio. Segundo Leite et al. (2005), os alimentos são formados por uma combinação de diferentes componentes e, por essa razão, geralmente, existem em um estado de não equilíbrio amorfo. Materiais amorfos são compostos susceptíveis às mudanças de temperatura e pressão do ambiente, de modo que pequenas variações nas condições ambientes podem provocar mudanças de estado em alguns componentes, causando mudanças estruturais indesejáveis, principalmente relacionadas ao teor de água.

Pôde-se observar no momento da filagem que as massas com menor tempo de refrigeração tiveram maior aptidão para filagem, quando foi possível utilizar temperaturas mais brandas. Segundo Furtado (1999), a umidade da massa é de extrema relevância no momento da filagem, pois a massa com umidade superior é também mais macia, podendo ser filada em condições de temperaturas mais baixas, tendo assim maior retenção de gordura, coalho e bactérias fermentativas em sua composição, o que auxiliaria muito em sua posterior estabilização.

\subsection{Características da água de filagem}


Os resultados referentes ao comportamento dos lotes de mussarela, quanto à perda de gordura e liberação de ácido láctico (acidez $\left.{ }^{\circ} \mathrm{D}\right)$ durante a filagem foram apresentados na Tabela 5.

Tabela 5 - Análise de acidez e gordura da água após a etapa de filagem da massa de Mussarela.

\begin{tabular}{ccc}
\hline Água após filagem & $\begin{array}{c}\text { Acidez } \\
\left(\mathbf{D}^{\mathbf{o}}\right)\end{array}$ & $\begin{array}{c}\text { Gordura } \\
(\boldsymbol{\%})\end{array}$ \\
\hline Mc & $12,66 \pm 0,33 \mathrm{D}$ & $1,20 \pm 0,05 \mathrm{D}$ \\
M1 & $16,66 \pm 0,33 \mathrm{C}$ & $1,90 \pm 0,05 \mathrm{C}$ \\
M2 & $18,66 \pm 0,33 \mathrm{~B}$ & $2,53 \pm 0,03 \mathrm{~B}$ \\
M3 & $32,00 \pm 0,57^{\mathrm{a}}$ & $3,36 \pm 0,08 \mathrm{~A}$ \\
\hline F & 91,33 & 218,76 \\
P & 0,01 & 0,01 \\
CV & 4,04 & 4,80
\end{tabular}

* Mc: Mussarela produzida com massa acidificada após 3h em refrigeração; M1: Mussarela produzida com massa acidificada após 12h em refrigeração; M2: Mussarela produzida com massa acidificada após 24h em refrigeração; M3: Mussarela produzida com massa acidificada após $36 \mathrm{~h}$ em refrigeração.

* Teste de Tuckey $(\mathrm{p}=0,05)$

* F: Valor do teste ; $p=0,05$; P: Significância; CV: Coeficiente de variação.

A acidez e a gordura da água de filagem são representadas pelo teor de ácido láctico e pela gordura da massa liberados durante o processo de filagem. Observando-se a Tabela 5, verifica-se que a massa filada após um menor tempo sob refrigeração durante o processo de acidifiação (Mc) tende a liberar menos ácido láctico na água de filagem. A quantidade de ácido lático tende a aumentar a medida que aumenta-se o tempo de refrigeração da massa, durante o processo de acidificação que antecede a filagem, como observado nos lotes M1, M2 e M3. Tal fato pode ser explicado pela desmineralização da massa pela acidez livre encontrada, o que aumenta também a perda de gordura no momento da filagem. Além disso, uma menor umidade nas massas as torna menos aptas para a filagem, tornando necessária a utilização de temperaturas superiores à da massa mais úmida, o que também contribui para a saída de gordura da massa para a água (FURTADO, 1999).

A água de filagem não é aproveitada pela indústria, representando um resíduo do processo tecnológico de fabricação da Mussarela, e segue para o setor de tratamento de efluentes da indústria. Dessa forma, quanto maior o teor de gordura na água de filagem, maiores serão os custos para o tratamento dessa água, uma vez que esta apresenta maior quantidade de matéria orgânica a ser digerida.

Analisando-se a Tabela 5, observa-se que existe diferença significativa $(p=0,05)$ entre os lotes avaliados. Dessa forma, observa-se que, quando se produz Mussarela utilizando-se o tempo de acidificação da massa sob refrigeração por 36 horas (M3), a quantidade de gordura liberada na água de filagem é muito maior que a água de filagem das outras amostras. 


\subsection{Características da Mussarela}

De acordo com o Regulamento Técnico de Identidade e Qualidade (RTIQ) que estabelece os padrões físico-químicos do queijo Mussarela, o produto deve apresentar em sua composição centesimal no máximo $60 \%$ de umidade e matéria gorda em extrato seco no mínimo 35\% (BRASIL, 1996). Na Tabela 6 foram apresentados os resultados das análises físico-químicas dos queijos Mussarela Mc, M1, M2 e M3, após 20 dias de estabilização da massa.

Tabela 6 - Características físico-químicas da Mussarela produzida com massa acidificada após 20 dias de estabilização.

\begin{tabular}{ccccccc}
\hline & $\begin{array}{c}\text { Umidade } \\
(\boldsymbol{\%})\end{array}$ & Gordura $(\boldsymbol{\%})$ & $\mathbf{p H}$ & $\begin{array}{c}\text { EST } \\
(\boldsymbol{\%})\end{array}$ & $\begin{array}{c}\text { ESD } \\
(\boldsymbol{\%})\end{array}$ & $\begin{array}{c}\text { GES } \\
(\boldsymbol{\%})\end{array}$ \\
\hline Mc & $45,33 \pm 0,33 \mathrm{~A}$ & $24,66 \pm 0,33 \mathrm{~A}$ & $5,06 \pm 0,03 \mathrm{~A}$ & $54,66 \pm 0,33 \mathrm{~B}$ & $30,00 \pm 0,57 \mathrm{C}$ & $45,06 \pm 0,76 \mathrm{~A}$ \\
M1 & $44,00 \pm 0,57 \mathrm{~A}$ & $24,00 \pm 0,57 \mathrm{~A}$ & $5,13 \pm 0,03 \mathrm{~A}$ & $56 \pm 0,57 \mathrm{~B}$ & $32,00 \pm 0,57 \mathrm{BC}$ & $42,81 \pm 0,91 \mathrm{AB}$ \\
M2 & $43,70 \pm 0,43 \mathrm{~A}$ & $23,80 \pm 0,61 \mathrm{~A}$ & $5,08 \pm 0,01 \mathrm{~A}$ & $56,30 \pm 0,43 \mathrm{~B}$ & $32,50 \pm 0,28 \mathrm{~B}$ & $42,20 \pm 0,80 \mathrm{AB}$ \\
M3 & $41,60 \pm 0,45 \mathrm{~B}$ & $23,43 \pm 0,32 \mathrm{~A}$ & $5,09 \pm 0,01 \mathrm{~A}$ & $58,40 \pm 0,45 \mathrm{~A}$ & $34,96 \pm 0,58^{\mathrm{a}}$ & $40,10 \pm 0,66 \mathrm{nB}$ \\
\hline F & 11,30 & 1,15 & 1,24 & 11,30 & 15,33 & 6,65 \\
P & 0,01 & 0,38 & 0,35 & 0,01 & 0,01 & 0,01 \\
CV & 1,82 & 3,47 & 0,86 & 1,41 & 2,79 & 3,22
\end{tabular}

* Mc: Mussarela produzida com massa acidificada após 3h em refrigeração; M1: Mussarela produzida com massa acidificada após 12h em refrigeração; M2: Mussarela produzida com massa acidificada após 24h em refrigeração; M3: Mussarela produzida com massa acidificada após 36h em refrigeração.

* UMD: Umidade no Extrato Seco; EST: Extrato Seco Total; ESD: Extrato Seco Desengordurado; GES: Gordura no Extrato Seco

* Teste de Tuckey $(\mathrm{p}=0,05)$

* F: Valor do teste ; $p=0,05$; P: Significância; CV: Coeficiente de variação.

Como pode ser observado na Tabela 6, as Mussarelas obtidas em todos os lotes analisados apresentaram-se dentro dos padrões exigidos pela legislação (BRASIL, 1996), com relação ao teor de umidade $(41,60 \%$ a $45,33 \%)$, gordura $(23,43 \%$ a $24,66 \%)$, pH $(5,06$ a 5,09$)$, EST $(54,66 \%$ a $58,40 \%), \operatorname{ESD}(30,00 \%$ a $34,96 \%)$ e $\operatorname{GES}(40,10 \%$ a $45,06 \%)$.

Vários fatores podem influenciar nas características do queijo Mussarela, por isso estudos na área vem sendo realizado para diagnosticar falhas no processo produtivo. Em estudo realizado por Viana (2012), o autor identificou falhas no processo produtivo da Mussarela em um laticínio localizado no município de Morrinhos -GO, como falhas na fabricação da massa acidificada e na filagem. $\mathrm{O}$ autor do trabalho acompanhou detalhadamente o fluxograma do queijo mussarela e constatou que falhas no momento da temperatura do ponto da massa, no caso aquém do desejado aumentou a umidade dos grãos tornando a mussarela mais pastosa e com dificuldades no posterior fatiamento. Também foram constatadas falhas no momento da filagem, como o uso de altas temperaturas $60{ }^{\circ} \mathrm{C}$ e excesso de acidez na filagem o que influiu diretamente na perda de gordura na filagem. Já no presente trabalho, foi verificado que o tempo do armazenamento da massa 
acidificada interfere significativamente nas características físico-químicas da Mussarela, a medida que esse tempo de estocagem previamente à filagem se alonga, como observado na Tabela 6.

Outro fator muito relevante para a qualidade final da Mussarela certamente é a qualidade da matéria-prima, em estudo Castro (2013) relata que a alta CCS influenciou nos tempos de coagulação e abaixamento de $\mathrm{pH}$, assim como nos rendimentos e qualidade dos queijos fabricados, comparando-se com os com menor taxa de CCS. Outro fator muito importante para qualidade do produto é a padronização do percentual de gordura, em estudo realizado por Valle et al. (2004), foi verificado que os queijos Mussarela fabricados com percentual de gordura de 2,5 à $3 \%$ obtiveram melhores resultados em quesitos muito importantes para a funcionalidade do queijo tais como fatiabilidade, a deformidade e a derretibilidade.

Pode-se observar que o lote do produto final que se apresentou com maior índice de umidade e gordura no extrato seco foi o Mc, diferindo significativamente ( $\mathrm{p}>5$ ) com M3, também o lote M3 apresentou maior extrato seco em relação ao Mc, o que acompanhou a tendência da analise da massa acidificada.

O período de estabilização é importante principalmente em queijos mussarela, pois é onde acontece a proteólise, lipólise e distribuição uniforme de sal no queijo através da osmose (FURTADO, 1999). Quando comparadas as Tabelas 4 e 6, observa-se que a massa acidificada manteve-se estabilizada, em todos os parâmetros analisados, com ligeira queda de umidade na Mussarela estabilizada, o que pode ser explicado pela expulsão da água pela concentração de sal no queijo.

\subsection{Rendimento da Mussarela}

Para o cálculo do rendimento da Mussarela, utilizou-se como referência o valor médio do preço do leite, de $\mathrm{R} \$ 1,00$ o litro e o preço do quilo da mussarela, de $\mathrm{R}$ \$ 12,00 ambos os preços são praticados pela empresa em estudo. Levou-se ainda em consideração que foram utilizados 10.000 litros de leite para fabricação de todos os lotes. 
Tabela 7 - Rendimento da Mussarela através do cálculo do volume de leite gasto para sua fabricação.

\begin{tabular}{cccc}
\hline Amostras & $\begin{array}{c}\text { Volume de leite gasto para } \\
\text { fabricação de 1Kg de } \\
\text { Mussarela }(\mathbf{L})\end{array}$ & $\begin{array}{c}\text { Volume de queijo } \\
\text { Mussarela produzido } \\
(\mathbf{K g})\end{array}$ & $\begin{array}{c}\text { Valor de } \\
\text { comercialização do } \\
\text { lote de mussarela }(\mathbf{R} \$)\end{array}$ \\
\hline Mc & 9,55 & $1,047.12$ & $12,565.44$ \\
M1 & 9,85 & $1,015.22$ & $12,182.74$ \\
M2 & 9,9 & $1,010.10$ & $12,121.12$ \\
M3 & 10,11 & 989,11 & $11,869.43$
\end{tabular}

* Mc: Mussarela produzida com massa acidificada após 3h em refrigeração; M1: Mussarela produzida com massa acidificada após 12h em refrigeração; M2: Mussarela produzida com massa acidificada após 24h em refrigeração; M3: Mussarela produzida com massa acidificada após 36h em refrigeração.

Pode-se observar, através da Tabela 7, que o rendimento diminuiu, nos lotes que ficaram mais tempo submetidos à temperatura de refrigeração. Esse fato pode ser atribuído à diminuição do teor de umidade na massa, conforme observado na Tabela 6, o que não é interessante do ponto de vista econômico, uma vez que é aumentado o custo de produção.

Quando comparados o valor comercial lote controle (Mc) e o lote que ficou mais tempo refrigerado (M3), observa-se uma diferença de $\mathrm{R} \$ 696,01$. Levando-se em consideração que são fabricados oito lotes de mussarela por dia isso, calcula-se que esse maior tempo, sob refrigeração, da massa acidificada anterior à filagem, geraria uma déficit de $\mathrm{R} \$ 5.568,08$ ao dia, $\mathrm{R} \$ 167.042,04$ ao mês e R $\$ 2.004 .508,80$ ao ano.

Dessa forma, verifica-se a necessidade de redução do tempo de acidificação da massa da Mussarela, que antecede a etapa de filagem, como forma de minimizar as perdas de umidade, durante a refrigeração, e de gordura na água de filagem, obtendo-se, ao final do processo, um melhor rendimento industrial. Portanto seria interessante um investimento na indústria para solucionar o problema verificado no presente estudo, como ampliação do setor de filagem, adquirindo maior número de máquinas e equipamentos.

\section{Conclusão}

Verificou-se que o melhor tempo de acidificação da massa, para produção de Mussarela, sob refrigeração, é de três horas, garantindo dessa forma um maior teor de umidade no produto final e, consequentemente, um maior rendimento industrial. Também foi verificado que, quando refrigerada por apenas três horas, ocorre uma menor liberação de gordura na água de filagem, reduzindo custos da indústria com o tratamento de efluentes.

Os resultados apresentados neste trabalho são extremamente importantes para as indústrias produtoras de queijos, uma vez que estas vêm aplicando processos tecnológicos inadequados no sentido de suprir alguma necessidade específica, como a de prolongar o tempo de armazenamento 
da massa da Mussarela em câmaras refrigeradas. Sendo assim, a empresa do presente estudo poderia enxergar as principais falhas e aplicar um efetivo controle de processo, no sentido de projetar possíveis soluções, que poderiam diminuir o tempo de espera da massa acidificada antes de ser filada.

\begin{abstract}
Before the mozzarella curd stretching step, the whey-free cheese mass must be acidified, and this time is usually carried out in three hours. The objective of this study was to evaluate the interference of acidified mass storage at low temperature, before the curd stretching process, on the rheological properties of mozzarella mass and the final yield cheese. Four lots were drawn up: Mc (control), with acidification time three hours under refrigeration; M1 (12h), M2 (24h) and M3 (36h). It was found that when the time under refrigeration for acidification of the mass is longer, prior to the step curd stretching, we can observe an increase of the moisture and fat in the curd stretching water. Thus, the industrial cheese yield is reduced, decreasing the profits of the dairies. It was concluded that investments are needed in curd stretching sector of this industry study aimed at promoting reduced time acidifying whey-free cheese mass, in order to ensure the maximization of profits.
\end{abstract}

Key-words: cheese; dairy technology; profit increase.

\title{
Referências
}

BRAGAnÇA, M. G. L.; SOUZA, C. M. Agroindústria. Processamento do Queijo Minas Frescal, Meia-Cura, Mussarela, MG, mar. $2001 . \quad$ Disponível em: <http://www.emater.mg.gov.br/site_emater/Serv_Prod/Livraria/Agroindustria>. Acesso em: 23 de Novembro de 2013.

BRASIL. Ministério da Agricultura e Abastecimento. Regulamentos Técnicos de Identidade e Qualidade de Produtos Lácteos. Ministério da Agricultura, Pecuária e Abastecimento. Portaria de 07 de Março de 1996, Diário Oficial da União, Brasília, 1996.

BRASIL. Ministério da Agricultura, Pecuária e Abastecimento. Instrução Normativa $n^{\circ} 62$ de 2003. Métodos Analíticos Oficiais para Microbiológicas para Controle de Produtos de Origem Animal e Água, Instrução Normativa $n^{\circ} 62$ de 2003. Diário Oficial da União, Brasília, 2003.

BRASIL. Ministério da Agricultura, Secretaria de Inspeção de Produto Animal. Regulamentos técnicos de produção, identidade, qualidade, coleta e transporte de leite. Instrução normativa n.51, de 18 de setembro de 2002 . Brasília, DF, 2002, 39p.

BRASIL. Ministério da Agricultura, Pecuária e Abastecimento. Métodos Analíticos Oficiais Físico-Químicos Produtos Lácteos. Instrução Normativa nº 68 .2006. Diário Oficial da União 14/12/2006.

CASTRO, K.A. Efeito da contagem de células somáticas sobre a qualidade dos queijos prato e mussarela. Urutaí, 2013. Monografia (Graduação em Tecnologia em Alimentos) - Departamento de Tecnologia em Alimentos - Instituto Federal Goiano - Campus Urutaí.

CAVAlchnte, F, M. Produção de queijos Gouda, Gruyére, Mussarela e Prato. Goiânia, 2004. Monografia (Graduação em Engenharia de Alimentos) - Departamento de Matemática e Física Engenharia de Alimentos Universidade Católica de Goiás.

EMBRAPA. Estatísticas do Leite. Disponível em:< http://www.cnpgl.embrapa.br/>. Acesso em: 06 de novembro 2010. 
FURTADO, M.M.; NETO, J. Tecnologia de Queijos - Manual para a Produção Industrial de Queijos. 1.ed. São Paulo: Editora Dipemar Ltda, 1994. 117p.

FURTADO, M, M. Principais problemas de queijos: causas e prevenção. São Paulo: Fonte Comunicação e Editora, 1999.

FAO. Previsões para o mercado internacional de lácteos. Disponível em < http://www.milkpoint.com.br/mercado/giro-lacteo/fao-previsoes-para-o-mercado internacional-de-lacteos73678n.aspx>.2010, Acesso em 06/02/2012.

LEITE, J, T, C.; MURR, F, E, X.; PARK, K, J. Transições de fases em alimentos: influencia no processamento e na armazenagem. Revista Brasileira de Produtos Agroindustriais, Campina Grande, v.7, n.1, p.83-96, 2005.

PERRY, K, S, P.; Queijos: aspectos químicos, bioquímicos e microbiológicos. Serviço de Química e Radioquímica, Comissão Nacional de Energia Nuclear, Centro de Desenvolvimento da Tecnologia Nuclear, CP 941, 30123-970. 2004, Belo Horizonte - MG.

PRATA, L. F. Fundamentos de ciência do leite. Jaboticabal: FUNEP-UNESP, 2001.

SILVA, F, T. Queijo mussarela. Embrapa Informação Tecnológica Brasília, DF, 2005.

VALLE, J.L.E.; CAMPOS, S.D.S.; YOTSUYANAGI, K.; SOUSA, G. Influência do teor de gordura nas propriedades funcionais. ITAL-Campinas, 2004.

VIANA L,F. Descrição do fluxograma e avaliação de alguns defeitos do queijo tipo mussarela. UFG-Goiânia 2012. 